\title{
Human Resources in the Digital Age A Manager's Realities and Perspectives
}

Cosmin TATARU ${ }^{1}$

\begin{abstract}
The world has experienced major cultural, social and economic changes, based on the growth of digital technology domination. In line with these changes, digital technologies play an increasingly important role in the life of employees and, human resources management seems to come to terms with it more and more.

What this article is proposing is to investigate whether the candidate, respectively, the employee - is ready to embrace all these changes?

The present paper work describes, within theoretical aspects and a practical analysis to identify the role of the human and digital component in the HR processes. How can teams take full advantage of advanced solutions without losing the "human" aspect of their organizational tasks?
\end{abstract} candidate

Keywords: professional career, human resources, management, digitization,

JEL classification: M10, M12, M16

DOI: $10.24818 / R M C I .2019 .4 .473$

\section{Introduction}

Technological improvement has an impact on the working environment and in particular on human resources management. Also, this area of inquiry is the object of study for consultancy companies and research institutes (Deloitte, 2017). The Global Human Capital Trends 2017 report, published by Deloitte, reflects significant changes in the business world. This new era of digitalization, also called the "Fourth Industrial Revolution" is characterized by an accelerated transformation, creating new rules for business and implicitly for human resource management. So, organizations face a radically changing concept for the workforce, the workplace, and the world of work. These changes modified the rules for almost every organizational practice, from management learning to the definition of work itself. (Deloitte, 2017). Companies are preparing avid in this area and are trying to find new tools and opportunities in digital absorption in HR: automatic posting of vacancies on social media, issuance of different certificates, timesheet and tax calculation, automatically identify online resources in order to prepare a pre-profile for the candidate before supporting an interview and even analyzing the candidate's

\footnotetext{
${ }^{1}$ Ec. Cosmin Tataru, Manager at BRD Groupe Société Générale, tataru_cosmin@yahoo.com
} 
behavior with the help of AI (artificial intelligence) during the employment interview.

\section{Digital Transformation-Challenge, risk or opportunity}

"Companies reinvent themselves. They become dynamic, team-based, and interconnected. Permanent change has, therefore, become a normal situation rather than a rare one." (Abrudan, 2018)

The development of information and communication technology (ICT) has undeniably played a vital role in the evolution of human resource management. Human Resource Management has also been profoundly affected by the development and has transformed the way organizations recruit, select, motivate, and retain employees (Stone et al., 2015).

Voermans and Van Veldhoven (2007) write, 'e-HRM could be narrowly defined as the administrative support of the HR function in organizations by using Internet technology' (p. 887). Voermans and Van Veldhoven (2007) write, 'e-HRM could be narrowly defined as the administrative support of the HR function in organizations by using Internet technology' (p. 887).

Following the "transactional" tradition, Voermans and Van Veldhoven (Voermans, Veldhoven, 2007) write as follows, "e-HRM could be narrowly defined as the administrative support of the HR function in organizations by using Internet technology."

Companies focus on redesigning the organization itself, studying and developing new models. Many organizations not only design but also build this new organization. As networks replace organizational hierarchies, the traditional question "who are you working for?" was replaced by the question "Who are you working with?".

By automating these processes, human resources technology has advanced to create an era of human resources professionals who see their roles not only as administrators but also as strategic factors for vital organizational decisions. Today, human resources are viewed as a portal rather than a person. Almost all businesses now offer universal access to human resource services through technological and web-based applications, which may dramatically change the practice of Human Resource management. These changes often result from the need to reduce costs and to expand or improve services. Recent research shows that organizations that successfully adopt sophisticated technology tools exceed those that do not. One of the challenges brought by digital transformation is undoubtedly represented by the introduction of a new software/or new online application. Adopting software solutions in HR processes plays a decisive role in digitization of this activity. Not only the HR Department is influenced by this kind of transformation, but also all the organizations are facing some problems - all the departments are now trying to implement digital solutions and to improve their flows. If the HR department of one organization will not adopt the same strategy, it is very possible that the company will not be ready for the future - the digitalization of HR is a must. 
However, would the human component be missing from the recruitment area? I certainly do not believe this, and I can undoubtedly certify that in the future, this component will be more important. The role of the human resource manager will be a more complex one because it will have as support an enormous mass data (Big data) that will help with an even better selection of the ideal candidate.

To sustain the transformation of the HR function, HR professionals must develop and demonstrate a new set of competencies to fulfil their changing roles and responsibilities (Yeung, et al, 1996). In the widely cited and used "Michigan's HR Competency Research," Brockbank, Ulrich, and James (1997) identified five significant competencies expected of HR professionals: strategic contribution, personal credibility, HR delivery, business knowledge, and HR technology. Becker et al. (2001) suggested adding strategic HR performance management as a sixth competency.

In his report for Altimeter, Brian Solis distinguishes six stages of digital transformation:

- Business as usual: business and meetings will run normally and naturally as in the present.

- Present and active: various experiments throughout the organization lead to digital literacy and creativity.

- Formalized: This shows the relevance of business. If it is not relevant to the company, management should not support such a transformation; although this does not always happen. Unfortunately, this is happening and, it is because some managers are not adapted to the digital area.

- Strategic: People create the power of collaboration. Their joint efforts and prospects have led to new strategic road maps (Solis, 2016). All that follows must have a digital component, and given that "all that means digitization" actually brings transformation, we can conclude that any future process will contain the notion of digital transformation.

- Convergent: A specialized Digital Transformation team is formed here to guide the company's strategy and operations.

- Innovative and adapt: digital transformation has become the new "business as usual," and a unique ecosystem is created. As mentioned above, any future project that will be implemented in a company must also contain aspects of "digital transformation."

By not adopting the "digital way," organizations risk being left out of the race to attract, maintain, and employ the candidates for a sustainable competitive advantage. Employee training and shared information are essential to mitigate risk. If you want to stay still competitive, you must be prepared for the future, and this future includes the digital area.

On the other hand, increasing the speed of digital adoption and the continuous emergence of new trends in HR technologies make it a critical concern for human resources departments. How can teams take full advantage of digital solutions without losing the "human" aspect of their organizational tasks? Are 
candidates ready and able to keep up with the accelerated digitalization processes proposed by companies?

Regarding human resources management, the literature contains numerous partial definitions that do not oppose each other but are rather complementary. Therefore, human resources management is "the result of specialized research and is based on the already known trajectory of relatively rapid evolution and diversification in many areas of activity." (Manolescu, A., 2001) This is a challenge due to the dynamic nature of people.

Larkin (2017) claims that "The change to the HR department that digital technology will bring will be all-pervasive and omnidirectional throughout every company."

Technological development "involves all areas, so that the organizational field does not constitute an exception. Technology has created tremendous potential for organizations to interact with employees. HR dedicated software will be developed, especially on your mobile phone and will use cloud technologies because people spend more and more time connected to the Internet and mobile devices. " (Abrudan, D., 2018)

With technological advances, its implications for companies and organizations are increasingly clear: start-up's that know a representative development augmentation become global leaders, digital consumption (artificial intelligence, autonomous cars, Big Data, cloud, customized production, 3D printers, Internet of Things, robots and drones, integrated social media platforms, augmented reality and virtual reality) reconfigures the traditional approach of the consumer through the appearance of a new type of employee in the labor market that is transforming at an accelerated rate.

Some of all the technologies and concepts presented previously will be a part of the future HR employees and therefore, of the HR recruiting process.

Robert Bolton said in the 2019 KPMG report: "The future of HR 2019: In the Know or in the No" that "those that 'get it' are acting decisively, viewing HR as a new value driver and turning to data, predictive insights and AI. The rest are either limiting themselves to changes that show some progress, perhaps through data and analytics initiatives, or only clinging to a static approach that's perilous." (Robert Bolton, KPGM, The future of HR 2019: In the Know or in the No, The gulf between action and inertia; 2019).

Perhaps the essential advantages of integrating the digitalization process into organizational processes are: the simplification of procedures, enhanced operational efficiency, and better measurement of a company's performance and facilitating the recruitment process of employees.

\section{Human resources, the force of development in any organization. Digitization as a resource- reinventing the concept of HR}

The digital industry affects existing organizational and managerial structures, which is most visible due to flexibility and fragmentation of work, 
methods of monitoring the changes, recruitment strategies, and qualification needs and training.

In the virtual world, digitalization is found in the form of smart operations. With innovative algorithms and data analysis, data is transformed into a new resource. This is the new currency, establishing the market position - the ultimate power. At the same time, the digital age empowers employees to assume their personal and professional life. Big data is an increasingly common notion used in HR language, and it is clear that in future this component if it is well structured and used, can bring plus value to the company that uses this information in the recruitment process.

Digital is changing how employees interact with their organizations (Spitzer, 2014) and there is a need for always-on HR technology as businesses no longer operate in the old traditional nine to five opening hours (Goldstein, 2014). Cianni and Steckler (2017) say that digital is going to have the most dramatic impact on the nature of work, including the work of HR professionals. They go on to say that senior HR professionals already see the value which can be obtained from selfservice portals, HR analytics and the inter-connectivity of various internal and external social media platforms.

"Over the past twenty years, digitalization has changed not only our economy, but also in everyday life, and it's expected that this process will continue for years to come. If digital technology initially represented a specialist market for specialists, it became a general-purpose technology that affects all sectors of the economy and society. "(European Commission, 2015). So "digitalization can be seen as the engine of transformation for the industry in the era of the internet economy." (Bauer, 2008)

Human resources don't disappear, and they reinvent themselves. The challenges faced by the companies are facing nowadays are very complex, closely intertwined, continually evolving.

Currently, "the ability to work with people in departments and various areas has become a key activity. Diversity is today a normalization; we all witness the emergence of multi-generational leadership that acquires new valences every two years. People who create new types of organizations are talented, brilliant, and build incredible results. They create the future." (Abrudan, 2018)

There is a tendency towards integrated business services for many human resource activities. Organizations across the globe are trying to create a uniform and high-quality approach for services offered. The table below shows the data from a survey of human resources professionals taken in late 1990, who were asked to classify the most important objectives and priorities of the profession (Eichinger and Ulrich, 1996). Six of the seven most essential priorities reported reflecting the needs of their organizations or the Human Resources unit. As can be seen, the promotion of diversity appears in 7 th place on their list. While it is difficult to foresee the future, it is still essential to identify and understand the fundamental social, economic and technological trends or "megatrends" that will affect business over the next ten to 
twenty years, to anticipate and prepare for subsequent transformations that will have to take place.

Table 1. Priorities and challenges of human resources

The seven top priorities that human resources managers need to address today

1. Helping their organization reinvent/redesign itself to compete more effectively

2. Reinventing the HR function to be a more customer-focused, cost-justified organization

3. Attracting and developing the next generation leaders and executives

4. Contributing to the continuing cost-containment/management effort

5. Continuing to work on becoming a more effective business partner with their line customers

6. Rejecting fads, quick fixes, and other HR fads; sticking to the basics that work

7. Addressing the diversity challenge

People want choices. They want some control over the processes that affect them, without having to deal with documents or wait too long. There is a mobile or web application for all today, including for traditional human resources functions. Self-Service becomes a trend, not only in our personal lives but also in the workplace.

\section{Conclusions}

Looking at the question from the beginning of this paperwork - is the company ready for the digital age? Is the candidate prepared to embrace and adapt quickly to the novelties brought by the digital age? There are some evident conclusions to be presented: First of all, companies have already understood for several years that they have to invest in IT services/solutions/applications and integrate them into their processes, including the human resources area.

Perhaps reluctant, in every company at first were taken over the applications for management of holidays (leave), tax services, management of vouchers and other administrative tools. Then a lot of organizations implemented in their processes the Robot Process Automation (RPA - developed by the Romanian Unicorn UiPath) that can issue electronic certificates and follow with accelerated steps to deep in the IT-sphere and integrate with the processes of HR applications. Another new technology can collect data about online candidates, applications that support certain behaviors during the interview or study the type of voice of the interlocutor

$478 \quad$ Volume 20, Issue 4, October 2019 Review of International Comparative Management 
(candidate) and automatically select a Human Resources advisor that is the most compatible with that type of candidate to support a telephone interview, etc.

The process of digital transformation in HR is only at the beginning, a few years ago only a small percentage of people were using social media for recruitment, and now the absence of social media in the recruitment process is inconceivable. Digital transformation in HR is here, and no matter how fast we adapt to the new, it depends only on the individual - whether he is the human resources manager or the candidate.

Even if you have now the role of a candidate, you must take some actions to understand and to be technically prepared to use all the applications that are on the market now and adapt to the ones that will come in the future of HR processes. Even if you are not ready now, it is not too late to look upon the future and start preparing.

\section{References}

1. Abrudan, D., 2018. The Big Challenges for Organizations in the Digital Era: Creating Value through Employee. West University of Timisoara, Romania

2. Becker, B., Huselid, M., \& Ulrich, D., 2001. The HR Scorecard: Linking People, Strategy, and Performance. Boston: Harvard Business School Press

3. Bauer, L., 2008. The virtual dimension in tourism: criteria catalog for the assessment of eTourism applications. In: O'Connor, P., Höpken, W., Gretzel, U. (eds.) Information and Communication technologies in tourism: proceedings of the international conference in Innsbruck 2008, pp. 522-532. Springer, Wien

4. Bob (Robert) Eichinger Dave Ulrich, Provocările resurselor umane, and Ulrich, Dave, 2009. The Society for Human Resource Management.

5. Brockbank, W., Ulrich, D., \& James, C., 1997. Trends in human resource competencies. Ann Arbor: University of Michigan School of Business.

6. Cianni, M. and Steckler, S. People \& Strategy. Spring, 2017. Vol. 40, Issue 2, pp. 14-19.

7. Deloitte Global Human Capital Trends, 2017. University Press.

8. Goldstein, Jill, 2015. Workforce Solutions Review., Vol. 6. Issue 1, pp. 28-29.

9. Larkin, J., 2017. HR Digital Disruption: The biggest wave of transformation

10. Manolescu, A., 2001, Managementul resurselor umane, ediţia a treia, Editura Economică, Bucureşti.

11. Robert Bolton, 2019. KPGM. The future of HR 2019: In the Know or in the No, The gulf between action and inertia; p. 2

12. Schwab, K., 2016. The Fourth Industrial Revolution. World Economic Forum.

13. Solis, B., 2016. The Six Stages of Digital Transformation, Altimeter Group.

14. Spitzer, B., 2014. Workforce Solutions Review. Vol. 5, Issue 1, pp. 15-17. 
15. Stone, D.L, Deadrick, D.L., Lukaszewski, K.M. \& Johnson, R., 2015. The influence of technology on the future of human resource management. Human Resource Management Review, 25, no. 5, 216-231.

16. Voermans, M., and Van Veldhoven, M., 2007. Attitude towards e-HRM: An Empirical Study at Philips. Personnel Review, 36, 6, 887-902.

17. Yeung, A., Woolcock, P., \& Sullivan, J. , 1996. Identifying and Developing Competencies for the Future. Human Resource Planning, 19(4), 48-58

18. Site UiPath, 2019. RPA Analyst Reports, available at https://www.uipath.com/company/rpa-analyst-reports

19. Ziarul Financiar, 2019. Marilena Popovici, B2 Holding: Pe zona de recuperare a creanţelor de retail ne bazăm foarte mult pe voice analytics available at https://www.zf.ro/banci-si-asigurari/marilena-popovici-b2holding-pe-zona-de-recuperare-a-creantelor-de-retail-ne-bazam-foarte-multpe-voice-analytics-18214402

20. COMMISSION STAFF WORKING DOCUMENT A Digital Single Market Strategy for Europe - Analysis and Evidence Accompanying the document Communication from the Commission to the European Parliament, the Council, the European Economic and Social Committee and the Committee of the Regions A Digital Single Market Strategy for Europe, 2015. Available at https://ec.europa.eu/info/sites/info/files/digital-single-market-swd_en.pdf 